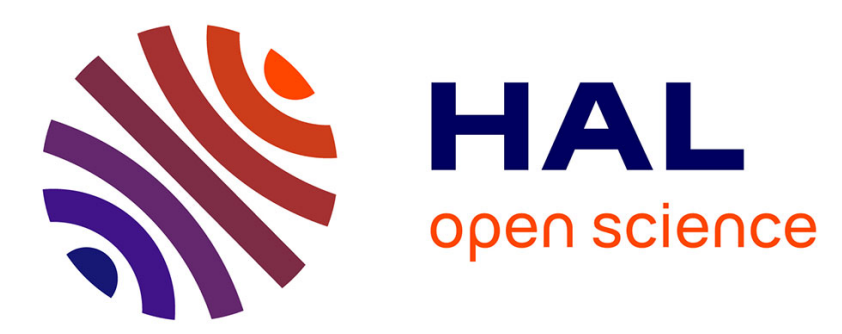

\title{
Wave Propagation in the Biosonar Organ of sperm whales using a Finite Difference Time Domain method
}

Maxence Ferrari, Ricard Marxer, Mark Asch, Hervé Glotin

\section{To cite this version:}

Maxence Ferrari, Ricard Marxer, Mark Asch, Hervé Glotin. Wave Propagation in the Biosonar Organ of sperm whales using a Finite Difference Time Domain method. VIHAR, Aug 2019, Lodon, United Kingdom. hal-02445408

\section{HAL Id: hal-02445408 \\ https://hal.science/hal-02445408}

Submitted on 20 Jan 2020

HAL is a multi-disciplinary open access archive for the deposit and dissemination of scientific research documents, whether they are published or not. The documents may come from teaching and research institutions in France or abroad, or from public or private research centers.
L'archive ouverte pluridisciplinaire HAL, est destinée au dépôt et à la diffusion de documents scientifiques de niveau recherche, publiés ou non, émanant des établissements d'enseignement et de recherche français ou étrangers, des laboratoires publics ou privés. 


\title{
Wave Propagation in the Biosonar Organ of sperm whales using a Finite Difference Time Domain method
}

\author{
Ferrari Maxence ${ }^{1,2}$, Ricard Marxer ${ }^{2}$, Mark Asch $^{1}$, and Hervé Glotin ${ }^{2}$ \\ ${ }^{1}$ LAMFA, CNRS, U. Picardie \\ ${ }^{2}$ Université de Toulon, Aix Marseille Univ, CNRS, LIS, Marseille, France
}

\begin{abstract}
The bio-sonar of sperm whales presents many specific characteristics, such as its size, its loudness or its vocalization abilities. Furthermore it fulfills several roles in their foraging and social behaviour. However our knowledge about its operation remains limited to the main acoustic path that the emitted pulse may take. We still ignore the precise mechanisms that shape the wave and on which parts the sperm whale is able to act. In this paper, we describe a technique to simulate sperm whale click generation from a physical perspective. Such an approach aims at unveiling the processes involved in their vocal production, as a stepping stone towards a better understanding of their interaction with peers and the environment.
\end{abstract}

\section{INTRODUCTION}

Sperm whales (Physeter macrocephalus, Pm) have the loudest bio-sonar in the animal kingdom ( $230 \mathrm{~dB}$ re: $1 \mu \mathrm{Pa} \mathrm{rms}$, Møhl et al. (2003)). The clicks produced by this sonar are not only used for their echolocation during dives, but also in their social interactions. During dives, sperm whales emit trains of clicks, much like those of bats, whereas for socialization, they will emit small rhythmic groups of clicks. Since Norris and Harvey (1972) first theorized the way their sonar worked, it has been broadly accepted that $P m$ creates an initial pulse at the front of its head, in the "museau de singe" (aka. monkey lips), which will then bounce back and forth in its head. However, the details of such a mechanism and which parameters the sperm whale can act on, remain unknown.

Since the 90's (Aroyan et al. (1992)), scientists have been modeling the propagation of vocalized sound waves in marine mammals heads. The ability to model wave propagation in marine mammals allows a better understanding of the interaction between all the organs responsible for the sound creation, or the molding of the sound wave, to achieve the highly directive beam pattern of such species (Cranford et al. (2008), Wei et al. (2014)). To the best of our knowledge these types of simulations have not been performed on the bio-sonar of sperm whales.

Most of these simulations are based on anatomic data derived from computed tomography (CT) scans. This information enables the construction of the model geometry, and to obtain the mechanical parameters for each material and their location (up to the CT scan resolution). However, most of the employed scans were performed on postmortem individuals. Cranford et al. (2014) compared data between dead and live specimens and their effects on the simulations. Dead specimen are prone to introducing artifacts in the model, such as air-filled blood vessels, but will not suffer from scanning errors due to the movement of a living specimen. However these deviations are likely not to change the mechanical parameters of the various tissues, and thus the Hounsfield unit that the CT-scan will measure, which has been shown (Soldevilla et al., 2005) to be correlated to the density and speed of sound.

In this work we describe a physical simulation of a $P m$ click using geometry and materials from dissection data and a Finite Difference Time Domain (FDTD) method for the wave propagation calculation.

\section{BUILDING THE GEOMETRY}

Unlike other small marine mammals, sperm whales cannot be CT-scanned by normal means due to their size and weight. The only tomography data available have been performed on postmortem neonate sperm 


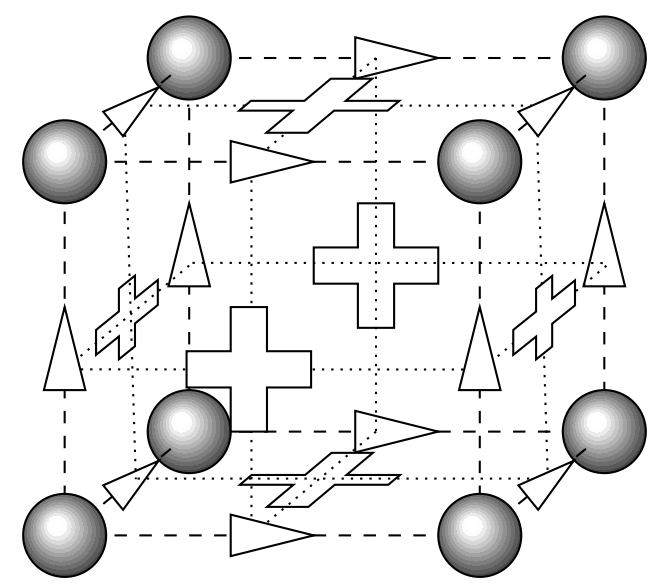

Figure 1. Part of the FDTD grid. Sphere : normal stress. Triangle : velocity. Cross : cross-stress

whales (Cranford (1999), Huggenberger et al. (2016)). However, those models cannot be simply scaled up since some anatomical elements do not match those of adult individuals obtained from dissections, such as the one shown in Clarke (1978). In order to shape our model we have used dissection data. We model each organ using Computer Assisted Design (CAD) software based on the slices from Clarke (1978). Since single blueprints did not match each other exactly, we had to scale some of them, or take the mean shape.

\section{FINITE DIFFERENCE TIME DOMAIN}

The method we used to simulate the sound propagation is a Finite Difference Time Domain (FDTD) approach, but unlike Aroyan et al. (2000), we use the stress-velocity equations which allows to model shear waves that propagate through cross-stress.

As usual for these sort of simulations, the aim is to simulate the target body inside an infinite medium. The standard way of getting rid of reflections from the border of the simulation, and thus simulating a infinite medium while treating only a finite box, consists either of having multiple dampening layers near the border, or having special equations for the border that will make them 'invisible' to waves. All of those methods are always an approximation and will still produce some reflections in certain cases. We have used the Absorbing Boundary Condition (ABC) from Higdon (1986), with angles of $2.86^{\circ}$ and $65^{\circ}$.

One iteration of the FDTD consists of the update of the speed grids, then the stress grids (including cross stress) and the ABC. The computation time of the boundary update is negligible compared to the stress and speed update (two orders of magnitude), and we could increase the number of angles of incidence with perfect absorption without any perceptible decrease in performance. However we consider this number of absorption angles to be enough.

\section{EXPERIMENT}

For our experiment we had to chose the mechanical parameters for each of the simulated media (skin, bones, spermaceti, water, etc.). While FDTD and our model are able to cope with anisotropic coefficients, for the sake of simplicity, in this first approach we have made an isotropic assumption. We have combined the measurements of Goold et al. (1996) (assuming a temperature of $30^{\circ} \mathrm{C}$ and atmospheric pressure), Clarke (1978) and the measurements done on the Kogia breviceps in Song et al. (2015). For the parameters not found in the literature, we have used values from the human body, based on the observation that the other parameter values are shared between the species (Physeter macrocephalus, Kogia breviceps, Ziphius cavirostris, Homo sapiens sapiens). The little variation introduced by the values borrowed from the other species will not have a significant impact on the results, since even a change of the order of $5 \%$ to $10 \%$ has little effect on the resultant beam (Cranford et al., 2008). The most important factor for the position of the various focal points is the geometry of the organs.

We simulated a sperm head in a $520 * 240 * 220 \mathrm{~cm}^{3}$ volume, with $1 \mathrm{~cm}$ resolution, and the materials were averaged following Toyoda et al. (2012). The simulation was implemented using PyTorch (a Deep 


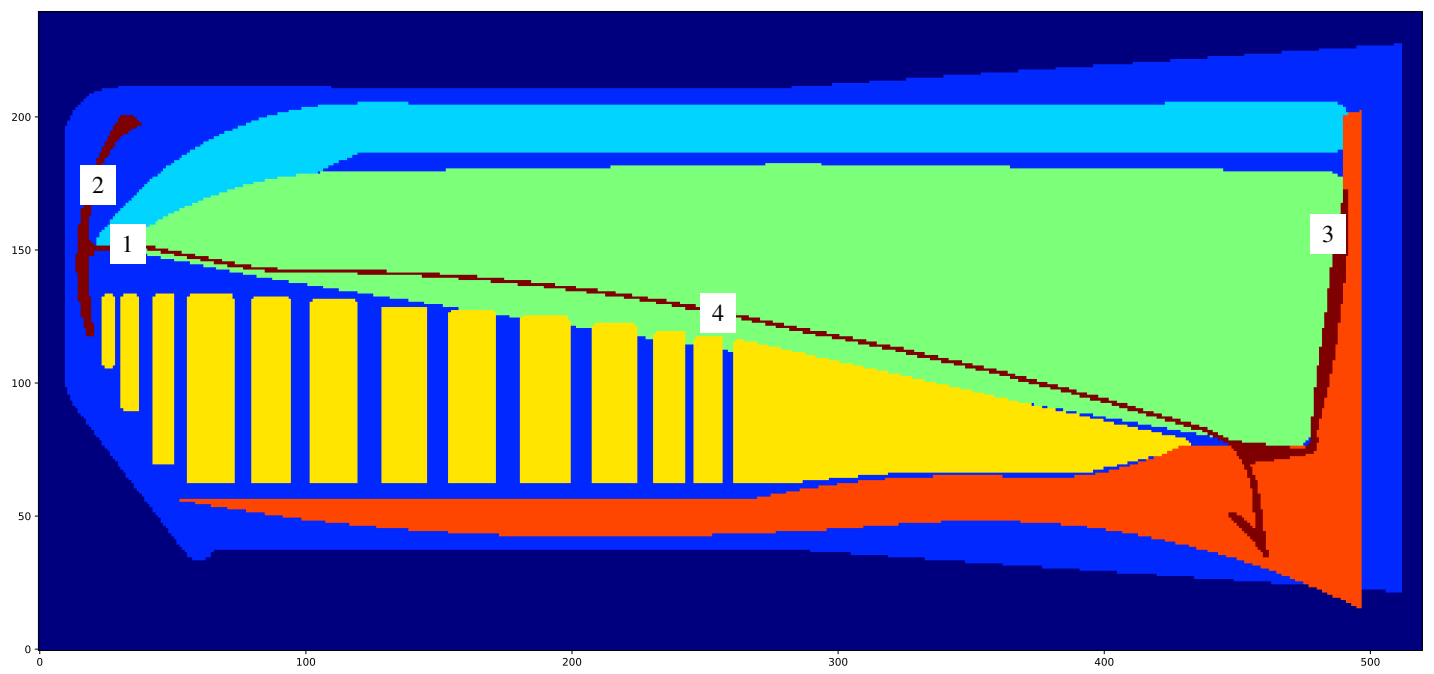

Figure 2. Material in the sagittal plane. Deep blue: water, blue: blubber and skin, cyan: muscle, yellow: junk, green: spermaceti, orange: bone, dark red: air. 1: museau de singe, 2: distal sac, 3: frontal sac, 4: right nasal passage.

Learning Python library) and run on an NVidia Titan X. The implementation performs at 4.6 iterations per second. Thus for a simulation of $20 \mathrm{~ms}$ with a time step of $1 \mu \mathrm{s}$, the computation time is $1 \mathrm{~h} 12$. The simulation starts at rest. We then add to pressure points located next to the museau de singe in the spermaceti the difference of a $10 \mathrm{kHz}$ sinusoidal wave during one period.

Figure 3 shows a recorded sound wave of a sperm whale click and the simulated pressure at the museau de singe. In both the recorded and simulated sounds we observe three pulses of a sperm whale click, in the simulated case these correspond to P0, P1 and P2. In the simulation we measure an offset of 6662 bins (or $\mu s$ ) between each of these pulses. These intervals are known as the inter pulse interval (IPI) and have often been used to estimate the total body length of the sperm whale (Clarke (1978), Gordon (1991), and Growcott et al. (2011)).

While the proposed model still fails to reproduce individual pulse wave shapes, such as those found in recorded vocalisations, it does produce a signal with a valid IPI. By using the three different methods cited above to estimate the body size from the IPI, we obtain sizes of $14.97 \mathrm{~m}, 14.47 \mathrm{~m}$ and $14.12 \mathrm{~m}$ respectively, which match the length of the actual sperm whale that the model is based on (14.2 $\mathrm{m})$. This result mainly depends on three parameters: the bulk modulus, the density, and the length of the spermaceti. Yet, it is still a comforting proof that this part of the model is working.

In Figure 4, we can see the evolution of the simulation, with the sound wave propagating from the museau de singe to the frontal sac, then being reflected by it, and going back to the museau de singe to be reflected by the distal sac.

\section{FUTURE WORK}

The model presented here remains a rough approximation and requires further tuning to better reflect the real phenomena. The geometry of the right nasal passage needs to evolve, in its current form it acts as a perfect mirror and prevents the energy reflected from the frontal sac to reach the junk. The next stages of this research will focus on the fluid-filled knobs present in the frontal sac described by Norris and Harvey (1972). During dives, they might act as a filter, thus modifying the response of the sonar.

\section{ACKNOWLEDGMENTS}

We thank Direction Générale de l'Armement and Région Hauts de France for the PhD grant of M. Ferrari. 

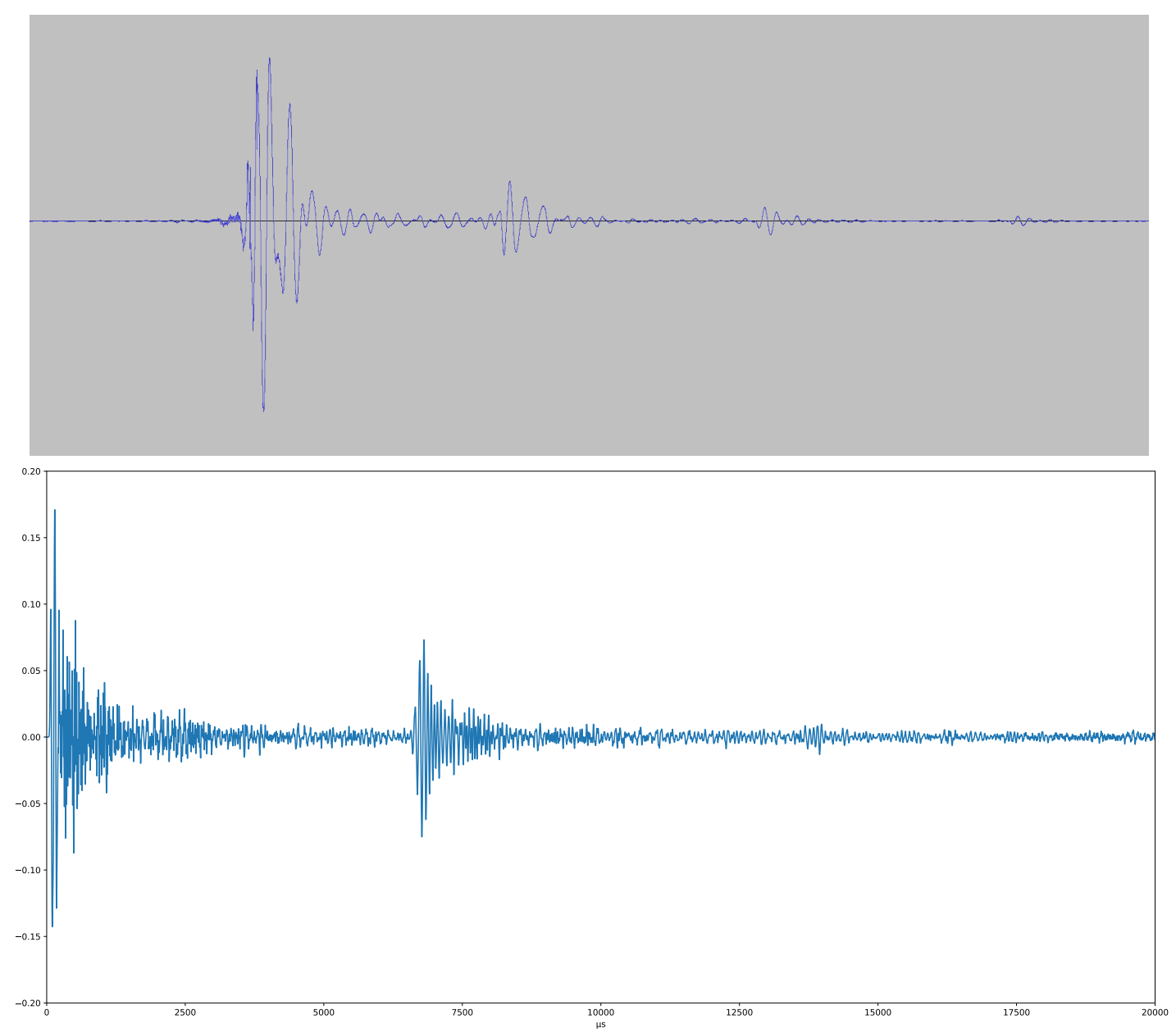

Figure 3. Top: Recording of sperm whale. Bottom: Simulated pressure at the excitation point. 

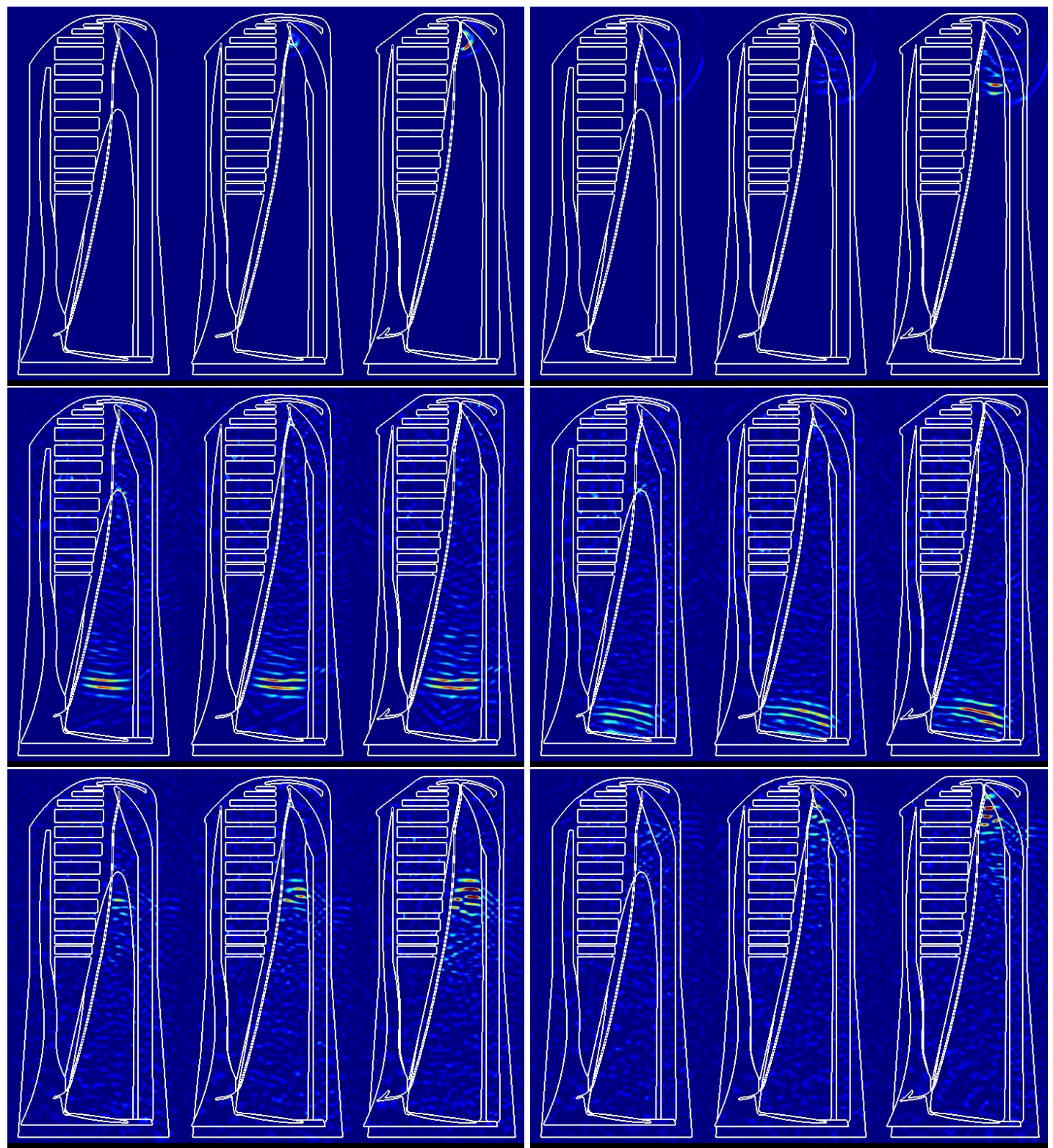

Figure 4. Multiple frames of the simulation, with the stress component (normalized) being plotted. Each picture is made of three slices of the 3D volume. The right one is the sagittal plane, the middle one is a plane $10 \mathrm{~cm}$ on the left of the sagittal plane, and the left one has an offset of $20 \mathrm{~cm}$ regarding the sagittal plane. Time steps shown are (top-left to bottom-right): 1s, 10s, 46s, 59s, 96s and 110s 


\section{REFERENCES}

Aroyan, J. L., Cranford, T. W., Kent, J., and Norris, K. S. (1992). Computer modeling of acoustic beam formation in d elphinusdelphis. The Journal of the Acoustical Society of America, 92(5):2539-2545.

Aroyan, J. L., McDonald, M. A., Webb, S. C., Hildebrand, J. A., Clark, D., Laitman, J. T., and Reidenberg, J. S. (2000). Acoustic models of sound production and propagation. In Hearing by whales and dolphins, pages 409-469. Springer.

Clarke, M. R. (1978). Structure and proportions of the spermaceti organ in the sperm whale. Journal of the Marine Biological Association of the United Kingdom, 58(1):1-17.

Cranford, T. W. (1999). The sperm whale's nose: Sexual selection on a grand scale? 1. Marine mammal science, 15(4):1133-1157.

Cranford, T. W., Krysl, P., and Hildebrand, J. A. (2008). Acoustic pathways revealed: Simulated sound transmission and reception in cuvier's beaked whale (ziphius cavirostris). Bioinspiration \& Biomimetics, 3(1):016001.

Cranford, T. W., Trijoulet, V., Smith, C. R., and Krysl, P. (2014). Validation of a vibroacoustic finite element model using bottlenose dolphin simulations: the dolphin biosonar beam is focused in stages. Bioacoustics, 23(2):161-194.

Goold, J. C., Bennell, J. D., and Jones, S. E. (1996). Sound velocity measurements in spermaceti oil under the combined influences of temperature and pressure. Deep Sea Research Part I: Oceanographic Research Papers, 43(7):961-969.

Gordon, J. C. (1991). Evaluation of a method for determining the length of sperm whales (physeter catodon) from their vocalizations. Journal of Zoology, 224(2):301-314.

Growcott, A., Miller, B., Sirguey, P., Slooten, E., and Dawson, S. (2011). Measuring body length of male sperm whales from their clicks: the relationship between inter-pulse intervals and photogrammetrically measured lengths. The Journal of the Acoustical Society of America, 130(1):568-573.

Higdon, R. L. (1986). Absorbing boundary conditions for difference approximations to the multidimensional wave equation. Mathematics of computation, 47(176):437-459.

Huggenberger, S., Andre, M., and Oelschläger, H. H. (2016). The nose of the sperm whale: overviews of functional design, structural homologies and evolution. Journal of the Marine Biological Association of the United Kingdom, 96(4):783-806.

Møhl, B., Wahlberg, M., Madsen, P. T., Heerfordt, A., and Lund, A. (2003). The monopulsed nature of sperm whale clicks. The Journal of the Acoustical Society of America, 114(2):1143-1154.

Norris, K. S. and Harvey, G. W. (1972). A theory for the function of the spermaceti organ of the sperm whale (physeter catodon 1.).

Soldevilla, M. S., McKenna, M. F., Wiggins, S. M., Shadwick, R. E., Cranford, T. W., and Hildebrand, J. A. (2005). Cuvier's beaked whale (ziphius cavirostris) head tissues: physical properties and ct imaging. Journal of experimental biology, 208(12):2319-2332.

Song, Z., Xu, X., Dong, J., Xing, L., Zhang, M., Liu, X., Zhang, Y., Li, S., and Berggren, P. (2015). Acoustic property reconstruction of a pygmy sperm whale (kogia breviceps) forehead based on computed tomography imaging. The Journal of the Acoustical Society of America, 138(5):3129-3137.

Toyoda, M., Takahashi, D., and Kawai, Y. (2012). Averaged material parameters and boundary conditions for the vibroacoustic finite-difference time-domain method with a nonuniform mesh. Acoustical Science and Technology, 33(4):273-276.

Wei, C., Zhang, Y., and Au, W. W. (2014). Simulation of ultrasound beam formation of baiji (lipotes vexillifer) with a finite element model. The Journal of the Acoustical Society of America, 136(1):423429. 